\title{
Correction to: Is Complete Pathologic Response in Pancreatic Cancer Overestimated? A Systematic Review of Prospective Studies
}

\author{
Laura Antolino ${ }^{1}$. Anna Crovetto ${ }^{1}$ Matteo Cinquepalmi ${ }^{1}$. Giovanni Moschetta ${ }^{1}$ - Maria Sole Mattei ${ }^{1}$. \\ Andrea Kazemi Nava ${ }^{2}$. Niccolò Petrucciani ${ }^{1}$ - Giuseppe Nigri ${ }^{1}$ - Stefano Valabrega ${ }^{1}$. Paolo Aurello ${ }^{1}$. \\ Francesco D'Angelo ${ }^{1} \cdot$ Giovanni Ramacciato'
}

Published online: 9 November 2021

(c) The Society for Surgery of the Alimentary Tract 2021

\section{Correction to: J Gastrointest Surg https://doi.org/10.1007/s11605-020-04697-1}

The author listing for this paper has been updated, the correct listing of authors is above.

Publisher's Note Springer Nature remains neutral with regard to jurisdictional claims in published maps and institutional affiliations.

The original article can be found online at https://doi.org/10.1007/ s11605-020-04697-1.

Matteo Cinquepalmi

matteo.cinquepalmi@uniroma1.it

1 General Surgery Unit, Department of Medical and Surgical Sciences and Translational Medicine, St. Andrea University Hospital, Sapienza University of Rome, Via di Grottorassa 1035, 00168 Rome, Italy

2 Hepatopancreaticobiliary Group, Saint Vincent's University Hospital, Dublin, Ireland 